\title{
Modelling Sustainable International Tourism Demand to the Brazilian Amazon
}

\author{
Jose Angelo Divino \\ Department of Economics \\ Catholic University of Brasilia \\ Michael McAleer \\ Department of Quantitative Economics \\ Complutense University of Madrid
}

\begin{abstract}
The Amazon rainforest is one of the world's greatest natural wonders and holds great importance and significance for the world's environmental balance. Around 60\% of the Amazon rainforest is located in the Brazilian territory. The two biggest states of the Amazon region are Amazonas (the upper Amazon) and Pará (the lower Amazon), which together account for around $73 \%$ of the Brazilian Legal Amazon, and are the only states that are serviced by international airports in Brazil's North region. The purpose of this paper is to model and forecast sustainable international tourism demand for the states of Amazonas, Pará, and the aggregate of the two states. By sustainable tourism is meant a distinctive type of tourism that has relatively low environmental and cultural impacts. Economic progress brought about by illegal wood extraction and commercial agriculture has destroyed large areas of the Amazon rainforest. The sustainable tourism industry has the potential to contribute to the economic development of the Amazon region without destroying the rainforest. The paper presents unit root tests for monthly and annual data, estimates alternative time series models and conditional volatility models of the shocks to international tourist arrivals, and provides forecasts for 2006 and 2007.
\end{abstract}

Key Words: Brazilian Amazon; International Tourism Demand; Time Series Modelling; Conditional Volatility Models; Forecasting.

JEL: C22; C53; Q23. 


\section{Introduction}

The Amazon rainforest holds great importance and significance for the world's environmental balance. As an idea of its importance and monumental size, the various rivers that comprise the Amazon basin account for around $20 \%$ of the total volume of fresh water that flows into the various oceans of the world. In short, the rivers of the Amazon region form the biggest hydrographic network anywhere on the planet. Specifically, the Amazon River is by far the world's biggest river in terms of fresh water volume. In addition, the biodiversity in the Amazon region is one of the richest of the world, with a considerable amount of fauna and flora that have been sighted by very few indigenous tribes and scientists. Medical researchers have suggested that the flora in the Amazon region can provide a cure in the years ahead for several diseases that afflict humanity.

Rainforests are effectively dense jungles. They are the oldest living ecosystem on Earth, covering about 6\% of its surface and accounting for two-thirds of the world's species of animals and plants. The Amazon represents over one-half of the world's remaining rainforests, and comprises the largest and most species-rich tract of tropical rainforest anywhere. There are temperate rainforests, that are found further north or south from Ecuador, and tropical rainforests, that are found along the warm and rainy climate of the Ecuador line. Tropical rainforests are known by their dense vegetation that forms three different layers, containing giant trees with a height of 75 meters or more in the upper layer. The soil of a rainforest is generally very poor due to the lack of sunlight and the high humidity. This combination of lack of sunlight and high humidity makes the soil especially fragile when the forest is destroyed, even entering into a process of desertification in some areas. 
The total extension of the Amazon rainforest is about 7 million square kilometers, and is distributed across nine South American countries, namely Bolivia, Brazil, Colombia, Ecuador, Guyana, French Guiana, Peru, Suriname, and Venezuela. Around $60 \%$ of the Amazon rainforest is located in the Brazilian territory, corresponding to virtually the entire North region of the country, and is called the Brazilian Amazon ${ }^{1}$. The remaining 40\% of the Amazon rainforest is distributed across the other eight countries that share the forest, with the largest part being in the eastern part of Peru. Large portions of the three Guineas, namely Guyana, Suriname and French Guiana, are covered by the Amazon rainforest.

The $60 \%$ of the Amazon that is located in the Brazilian territory defines the socalled Legal Amazon, and includes the states of Acre, Amazonas, Amapá, North of Mato Grosso, Pará, Rondônia, Roraima, Tocantins, and West of Maranhão. Figure 1 presents a map of Brazil that emphasizes these states. Although Maranhão is actually a state of the Brazilian Northeast region, it borders the east side of Pará state, which means that its border on the West of Maranhão is covered by the Amazon forest, and hence is a part of the Legal Amazon. The same holds for North of Mato Grosso, which is a state of the Middle-East Region that borders South of Amazonas and Pará and West of Rondonia. The two biggest states of the Amazon region are Amazonas (also referred to as the upper Amazon) and Pará (also referred to as the lower Amazon), which together account for around 73\% of the Brazilian Legal Amazon.

Amazonas is the largest state of Brazil, with a total area of 1.6 million square kilometres. This state is larger than any other country of the Amazon rainforest, and virtually all of its area is occupied by rainforest or rivers. In addition to its size, Amazonas state is surrounded by land, such that access to the region is by air or along

\footnotetext{
${ }^{1}$ All the geographical data presented in this section has as source the official site of the Brazilian Institute for Geography and Statistics (IBGE, Instituto Brasileiro de Geografia e Estatística), avalaible at www.ibge.gov.br.
} 
the various rives that form the Amazon River and its tributaries. Large ships have access to Amazonas from the Pará city of Belem, which is at the mouth of the Amazon River where it flows into the Atlantic Ocean.

The capital of Amazonas state is Manaus, which is at the confluence of the two main tributaries of the Amazon River, where the black water of the Rio Negro and the yellowish brown water of the Rio Solimoes join to form the Amazon River. About 77\% of the Amazonas state forest remains intact, primarily due to the creation of the Free Zone of Manaus (Zona Franca de Manaus) by the Brazilian Government in 1967 to implement light industries in the region, mainly electronics and motorcycles. This affirmative action has created job opportunities around Manaus and has contributed to preserve the rainforest from being exploited for (possibly unsustainable) economic activities. There have been significant efforts made by the Federal Government to promote sustainable development in the region in order to preserve the natural resources. The local economy is based on the light industrialization of the Free Zone of Manaus, explorations for petrol and natural gas, fishing, mining, and natural exploration. Several projects have recently been initiated in the region, including technological innovation, biodiversity exploration, sustainable tourism, eco-tourism, and education, all of which have been linked to widespread concerns about sustainable economic development and growth.

The second largest Brazilian state is Pará, which has a total area of 1.2 million square kilometers. Much of the Pará territory is also covered by the Amazon rainforest. The discovery and extraction of latex from rubber trees was responsible for the development of the state towards the end of the $19^{\text {th }}$ century and beginning of the $20^{\text {th }}$ century. With the economic decline of natural latex and its replacement with synthetic rubber, Pará experienced economic stagnation, which was overcome in around 1960s 
with the development of commercial agriculture and mineral exploration, mainly iron and gold, in the south of the state.

As it might be expected, economic progress has been achieved at the cost of destroying large areas of the Amazon rainforest. For example, there has been the creation of an industrial zone around the metropolitan region of Belem, the Pará state capital, and illegal extraction of wood from the Amazon forest. More recently, widespread commercial agriculture and the bovine industry have moved toward the southeast of the state, which has led to serious land conflicts and further destruction of the Amazon rainforest.

In this scenario of destruction and illegal exploration of the rainforest, the tourism industry would seem to have the potential to contribute to sustainable economic development in the North region of Brazil. Activities linked to ecotourism, for instance, would be a rational way of generating employment and income to the region without causing damage to its abundant natural resources. However, tourism, especially international tourism, is still in its infancy in the Amazon region. In this context, Figure 2 shows the distribution of tourism GDP, as computed for each Brazilian municipal district by Divino et al. (2007). It is strikingly clear that tourism GDP is heavily concentrated along the Northeast coastline and in the Southeast and South regions of the country. In the North region, very few municipal districts show tourism GDP at the upper level of the distribution, with much of the states of Amazonas and Pará having very low tourism GDP. The sole exception to the low tourism GDP in the upper Amazon rainforest is the Free Zone of Manaus. In general, tourism GDP in the upper Amazon is extremely low, except in some cities and towns along the Amazon River and its various tributaries. 
The primary purpose of this paper is to model and forecast sustainable international tourism demand for the Brazilian Amazon. By sustainable tourism is meant a distinctive type of tourism that has a lesser impact on the natural environment, local communities and local cultures, as opposed to other economic activities that have caused destruction of large areas of the rainforest. We will analyse international tourist arrivals data for the two major states in the Amazon region, namely Amazonas and Pará, which are the only states that are serviced by international airports in Brazil's North region. As mentioned previously, these two states account for around $73 \%$ of the Brazilian Amazon, and are also the only two states in the Brazilian Amazon for which monthly time series data over an extended period are available. In terms of the existent literature, this paper may be seen as a precursor for future analyses of sustainable tourism in the Brazilian Amazon region as there would seem to be no previous research that has modelled and forecasted international tourist arrivals to the Brazilian Amazon using reliable monthly time series data.

The development of a sustainable tourism industry would seem to be crucial for the North region as it is presently the second poorest region in Brazil. Table 1 shows the GDP and per capita GDP figures for each of the 27 Brazilian states and the 5 broad regions. It shows that the per capita GDP of the North region is only US\$1,509. Of the 7 states in the North region, marked in bold, 4 of them are among the 10 poorest states in Brazil. Maranhão, which borders Pará state, is the poorest Brazilian state on the basis of per capita GDP. Only the Amazonas state is among the top 10 states in Brazil. As mentioned previously, the ranking of Amazonas state arises primarily because of the Free Zone of Manaus that has generated employment and increased income through light industrialization around the state's capital, without destroying the Amazon rainforest. It is envisaged that, with the development of sustainable exploration by local 
governments and private sector, international tourism can contribute significantly to the sustainable economic development of the North region.

The tourism industry is still very underdeveloped in the Brazilian Amazon, but has great potential for expansion. In 2007, for instance, the number of international tourists arriving in Amazonas and Pará accounted for only 0.6\% and 0.5\%, respectively, of the total number of international tourist arrivals to Brazil. Historically, within each of these states, most of the tourist have come from the USA to Amazonas (51\% in 2007) and from French Guiana to Pará (46\% in 2007). Other important sources of international tourists are Canada and Venezuela to Amazonas and the USA and France to Pará. Most of the international tourists come to these two regions because they are attracted by ecotourism, followed by commerce in the free trade zone of Manaus, and also for medical purposes. These two regions are not popular with domestic tourists, with very few Brazilians travelling to the region.

There has recently been a growing literature that has applyied econometric techniques to forecast tourism demand. Athanasopoulos et al (2009) provide hierarchical forecasts for Australian domestic tourism demand, and produce detailed forecasts of the Australian domestic tourism market. Bonham et al (2009) estimate a fully identified vector error correction model of tourism for Hawaii, where both demand and supply-side influences are important. They identify long run equilibrium relationships and demonstrate satisfactory forecasting performance. Gil-Alana et al (2009) apply different seasonal statistical models to forecast the numbers of tourists travelling to the Canary Islands, Spain, and use different forecasting models for short versus long run forecasts. Other important contributions to the tourism and environmental forecasting literature include Ribbe et al. (2008), Anwar et al (2007), and Ticehurst et al (2007). This paper contributes to the literature by modelling and 
forecasting international tourist arrivals to the Brazilian Amazon using reliable monthly and annual time series data. It is the first paper that examines the usefulness of, such models and provides forecasts of sustainable tourism demand for the Brazilian Amazon.

The structure of the remainder of the paper is as follows. Section 2 discusses the monthly and annual international tourist arrivals to Amazonas, Pará and the total of the two states. Section 3 presents unit root tests for the monthly and annual data to be analysed. Alternative time series models for international tourist arrivals and conditional volatility models are presented in Section 4, and their estimates are given in Section 5. Forecasts of monthly and annual international tourist arrivals to Amazonas, Pará and the total of the two states for 2006 and 2007 are given in Section 6. Some concluding remarks are given in Section 7.

\section{Data}

The data set to be analysed consists of monthly time series data, as well as annual aggregates, relating to international tourist arrivals for the two major states of the Brazilian Amazon, namely Amazonas and Pará, for the period January 1971 to December 2005. The sources of the data are the official reports of Embratur (Empresa Brasileira de Turismo - Brazilian Enterprise of Tourism), which is an official branch of the Federal Ministry of Tourism that is responsible for the compilation of tourism statistics in Brazil. According to the Embratur statistical department, the numbers of international tourist arrivals are computed from immigration cards that international tourists are required to complete and submit to the Brazilian Federal Police before entering the country. For the Brazilian Amazon, the immigration cards are tabulated from the international airports in Manaus, the capital of Amazonas, and Belém, the 
capital of Pará. In addition to monthly data, we have also used annual data in estimation and forecasting. The major advantages of using monthly data are to increase the sample size from 35 annual observations to 420 monthly observations, and to investigate the volatility that is inherent in the time series, which is a requirement for estimating conditional volatility models accurately (for further details, see McAleer (2005)). The annual tourist arrivals series correspond to the monthly aggregates for each year. In the empirical analysis, we also consider the total number of international tourist arrivals for Amazonas and Pará for both the monthly and annual time series, which are obtained by adding the international tourist arrivals to the Amazonas and Pará states.

At the outset, it should be mentioned that there were nine missing observations for the monthly series of international tourist arrivals for the Amazonas state in 1993. According to Embratur, the missing monthly data arose from administrative problems at the International Airport of Manaus. In order to obtain a complete and homogeneous series of observations for both Amazonas and Pará, we estimated an ARMA model for the monthly data to December 1992, then forecasted all 12 months of 1993, and used the 3 months in 1993 for which there were observations to calibrate the accuracy of the forecasts. Estimation of several alternative specifications with 12 seasonal dummy variables suggested that the best fitting models were an unrestricted AR(2) model and AR(12) model with zero restrictions for lags 3-11 inclusive. The Akaike Information Criterion and Schwarz Bayesian Information Criterion slightly favoured the unrestricted AR(2) model, but the aggregated forecasts for 1993 were very similar, namely 12,551 and 12,557, respectively. As the AR(12) term was only marginally significant at the $1 \%$ level, but resulted in a loss of 10 observations, the unrestricted AR(2) model with 12 monthly seasonal dummy variables was used to forecast the monthly international tourist arrivals to the Amazonas state for the 12 months of 1993. 
The calculation of missing monthly observations for Amazonas for 1993 leads to the use of generated regressors for purposes of forecasting, with the associated critical issues of generally inefficient estimation and invalid inferences that arise through the use of biased (asymptotic) standard errors in the presence of sampling estimation errors. Pagan (1984, 1986), Oxley and McAleer (1993, 1994), and McKenzie and McAleer (1997) provide comprehensive discussions of these issues, including the impact of generated regressors on obtaining forecasts and forecast standard errors.

The complete time series for monthly and annual international tourist arrivals are displayed in Figures 3 and 4, respectively. These figures also show the respective growth rates. From Figure 3, it is evident that there is an important seasonal component but no deterministic trend component in the monthly series of international tourist arrivals. As a result, the growth rates fluctuate around zero over time, with noticeable volatility persistence in the monthly growth rates. In addition, the monthly time series data are generally quite small numbers. For Amazonas, the monthly average of international tourist arrivals was 1,093, with a maximum of 4,109 in January 1987 and an amazing minimum of 2 in July 1991. For Pará, the situation is reasonably similar, with a monthly average of 903 international tourist arrivals. However, the Pará time series peaked in July 2005 with 4,394 international tourist arrivals, and with a minimum of an extremely low 6 in October 1988. The monthly growth rates in international tourist arrivals showed significant volatility, varying roughly between $(-350 \%, 350 \%)$ for Amazonas, $(-400 \%, 500 \%)$ for Pará, and $(-140 \%, 130 \%)$ for the total of the two leading states.

On an annual basis for the period 1971-2005, the average number of international tourist arrivals to Amazonas was 13,114, while this number was lower at 10,839 for Pará. From Figure 4, it is evident that there is no tendency for the growth in 
the number of international tourist arrivals to increase deterministically over time as the annual growth rates have been close to zero for Amazonas, Pará and the sum of the two states since 1971. The annual growth rates in international tourist arrivals were less volatile than their monthly counterparts, and varied roughly between $(-60 \%, 50 \%)$ for Amazonas, $(-90 \%, 90 \%)$ for Pará, and $(-50 \%, 50 \%)$ for the total of the two leading states.

The numbers of international tourists suggest that international tourism activity has not been encouraged in the Brazilian rainforest. The Brazilian Amazon is one of the richest geographic locations in the world for biodiversity, but the second poorest in Brazil in terms of per capita income. Thus, the development of a sustainable tourism industry should be able to preserve the rainforest and to generate substantial income for the residents of the Amazon rainforest region.

\section{Unit Root Tests}

The first step in the modelling strategy was to test the time series for the existence of one or more unit roots. A common criticism of traditional unit root tests, primarily those based on the classic methods of Dickey and Fuller $(1979,1981)$ and Phillips and Perron (1988), is that they suffer from low power and size distortions. However, these shortcomings have been overcome by modifications to the testing procedures, such as the methods proposed by Perron and Ng (1996), Elliott, Rothenberg and Stock (1996), and Ng and Perron (2001).

For example, Elliott, Rothenberg and Stock (1996) demonstrate that OLS detrending is inefficient if the data presents high persistence, and suggest using GLS detrended data, which is efficient. Ng and Perron (2001) show that, in the presence of a 
strong negative moving average coefficient, the unit root estimate is strongly biased if the lag truncation, $\mathrm{k}$, is small because the residuals of the test equation are serially correlated. In order to select the optimal value of $\mathrm{k}$ to account for the inverse non-linear dependence between the bias in the unit root coefficient and the selected value of $k$, and to avoid selecting an unnecessarily large value of k, Ng and Perron (2001) proposed a modified Akaike Information Criterion (MAIC). Thus, the modified ADF $\left(M A D F^{G L S}\right)$ test uses GLS de-trended data and the MAIC in order to choose the truncation lag.

The modified Phillips-Perron test $\left(M P P^{G L S}\right)$, which also uses GLS de-trended data and the MAIC to select the optimal truncation lag, is due to Phillips and Perron (1988), Perron and Ng (1996) and Ng and Perron (2001). The asymptotic critical values for both the $M A D F^{G L S}$ and $M P P^{G L S}$ tests are given in Ng and Perron (2001).

The results of the unit root tests, which are obtained from the econometric software package EViews 5.0 and reported in Table 2, indicate that the logarithm of monthly international tourist arrivals for Amazonas (LAM) and the total of Amazonas and Pará (LTO) have unit roots. For Pará (LPA), however, the tests indicate a stationary time series. The annual data also indicate a stationary series for Pará. In the model with just a constant as the deterministic term, however, the null hypothesis of a unit root is rejected for Amazonas at the 5\% level of significance. The aggregate of Amazonas and Pará (LTO) is still non-stationary. Unit root tests were also applied to the monthly data that were seasonally adjusted using the X11 method of the U.S. Census Bureau, but there were no significant quantitative changes to the results.

In view of these empirical results, the first differences in the logarithms of international tourist arrivals are used in estimating the models given below. This transformation was deemed preferable as it would guarantee that all the time series are 
stationary and also provide the rate of growth of international tourist arrivals to Amazonas, Pará, and the aggregate of the two states.

\section{Conditional Mean and Conditional Volatility Models}

The alternative time series models to be estimated for the conditional means of the monthly and annual international tourist arrivals, as well as their conditional volatilities, are discussed below. As Figure 3 illustrates, the growth rates of international tourist arrivals to Amazonas, Pará and the total of the two states show periods of high volatility followed by others of relatively low volatility. One implication of this behavior is that the assumption of homoskedastic residuals is inappropriate. In this case, in order to forecast the international tourist arrivals (or their growth rates, as appropriate), it is necessary also to forecast their conditional variances.

Time-varying conditional variances can be explained empirically through the autoregressive conditional heteroskedasticity (ARCH) model, which was proposed by Engle (1982). When the time-varying conditional variance has autoregressive and moving average components, this leads to the generalized $\operatorname{ARCH}(p, q)$, or $\operatorname{GARCH}(p, q)$, model of Bollerslev (1986). The lag structure of the appropriate GARCH model can be chosen by information criteria, such as those of Akaike and Schwarz, although it is very common to impose a GARCH(1,1) specification in advance. In the selected conditional volatility model, the residual series should follow a white noise process. Li et al. (2002) provide an extensive review of recent theoretical results for univariate and multivariate time series models with conditional volatility errors, and McAleer (2005) reviews a wide range of univariate and multivariate, conditional and stochastic, models of volatility. 
Consider the stationary AR(1)-GARCH(1,1) model for international tourist arrivals (or their growth rates, as appropriate), $y_{t}$ :

$$
y_{t}=\phi_{1}+\phi_{2} y_{t-1}+\varepsilon_{t}, \quad\left|\phi_{2}\right|<1
$$

for $t=1, \ldots, n$, where the shocks (or movements in international tourist arrivals) are given by:

$$
\begin{aligned}
& \varepsilon_{t}=\eta_{t} \sqrt{h_{t}}, \quad \eta_{t} \sim \operatorname{iid}(0,1) \\
& h_{t}=\omega+\alpha \varepsilon_{t-1}^{2}+\beta h_{t-1},
\end{aligned}
$$

and $\omega>0, \alpha \geq 0, \beta \geq 0$ are sufficient conditions to ensure that the conditional variance $h_{t}>0$. The AR(1) model in equation (1) can easily be extended to univariate or multivariate $\operatorname{ARMA}(p, q)$ processes (for further details, see Ling and McAleer (2003a)). In equation (2), the ARCH (or $\alpha$ ) effect indicates the short run persistence of shocks, while the GARCH (or $\beta$ ) effect indicates the contribution of shocks to long run persistence (namely, $\alpha+\beta$ ). The stationary $\operatorname{AR}(1)-\operatorname{GARCH}(1,1)$ model can be modified to incorporate a non-stationary $\operatorname{ARMA}(p, q)$ conditional mean and a stationary $\operatorname{GARCH}(r, s)$ conditional variance, as in Ling and McAleer (2003b).

In equations (1) and (2), the parameters are typically estimated by the maximum likelihood method to obtain Quasi-Maximum Likelihood Estimators (QMLE) in the absence of normality of $\eta_{t}$. The QMLE is efficient only if $\eta_{t}$ is normal, in which case it is the MLE. When $\eta_{t}$ is not normal, adaptive estimation can be used to obtain efficient 
estimators. Ling and McAleer (2003b) investigate the properties of adaptive estimators for univariate non-stationary ARMA models with $\operatorname{GARCH}(r, s)$ errors.

Ling and McAleer (2003a) showed that the QMLE for $\operatorname{GARCH}(p, q)$ is consistent if the second moment of $\varepsilon_{t}$ is finite. For $\operatorname{GARCH}(p, q)$, Ling and Li (1997) demonstrated that the local QMLE is asymptotically normal if the fourth moment of $\varepsilon_{t}$ is finite, while Ling and McAleer (2003a) proved that the global QMLE is asymptotically normal if the sixth moment of $\varepsilon_{t}$ is finite. Using results from Ling and Li (1997) and Ling and McAleer (2002a, 2002b), the necessary and sufficient condition for the existence of the second moment of $\varepsilon_{t}$ for $\operatorname{GARCH}(1,1)$ is $\alpha+\beta<1$ and, under normality, the necessary and sufficient condition for the existence of the fourth moment is $(\alpha+\beta)^{2}+2 \alpha^{2}<1$. Extensions of several of these results for asymmetric conditional volatility models are given in McAleer et al. (2007).

\section{Estimates of Models}

The empirical results for the estimated models, which are obtained using the econometric software package package EViews 5.0, are reported in Table 3. For the monthly growth rate of international tourist arrivals to Amazonas, all the estimated coefficients are statistically significant at the 5\% level. The AR(12) term was included in the model to capture seasonal factors. The $\operatorname{GARCH}(1,1)$ coefficients indicate that the persistence of shocks to Amazonas holds in both the short and long run, with the short run persistence being quite small, though statistically significant. The AR(1) coefficient of 0.41 implies that the growth rate of Amazonas is convergent. The diagnostic test, provided by a Lagrange multiplier (LM) test for ARCH disturbances, indicates that there is no need to include additional lags in the $\operatorname{GARCH}(1,1)$ specification. As the 
second and fourth moment restrictions, as given in Section 4, are satisfied for Amazonas, the QMLE are consistent and asymptotically normal, so that standard statistical inference is valid.

The estimated model for the monthly growth rate of international tourist arrivals to Pará presented some coefficients that were not statistically significant. Specifically, the constant and the GARCH(1) term were not statistically different at the 5\% level. The AR(1) coefficient was negative and close to zero, indicating a convergent process. The GARCH(1,1) coefficients, however, suggest a very high persistence of shocks to Pará in the short run, with the ARCH effect being 0.99, with the long run persistence being quite small and insignificant at 0.07 . The LM diagnostic test indicates that the model is well specified for the selected GARCH terms.

The estimated model for the total of international tourist arrivals to the Amazonas and Pará states shows that all the estimated coefficients, except for the constant, are statistically significant. This time series is also convergent, given the estimated AR(1) coefficient of 0.44 , which is far inside the unit circle. The estimates of the GARCH(1,1) model imply that the persistence of shocks decays very slowly for the growth rate of the aggregate monthly data, with the short run persistence being small, though statistically significant. The GARCH $(1,1)$ coefficients indicate that the persistence of shocks to Pará holds in both the short and long run, and the results for the LM test suggest that the model is well specified. As for Amazonas, there is a strong negative MA coefficient for the aggregated series. Moreover, the second and fourth moment restrictions are satisfied for the aggregates series, as for Amazonas, so the QMLE are consistent and asymptotically normal, so that standard statistical inference is valid. 
For the annual data, it is interesting to note that there are no GARCH effects for any of the three time series. This is in accordance with Figure 4, where the annual growth rates of international tourist arrivals show a reasonably constant variance throughout much of the sample period. The LM tests for the estimated ARMA models indicate that there is no $\mathrm{ARCH}(1)$ or $\mathrm{ARCH}(2)$ effects in the estimated residuals. Thus, the conditional variance of the residuals is constant over the period. In addition, the estimated AR(1) coefficients are inside the unit circle, implying that the annual growth rates are convergent.

\section{Forecasts of Monthly and Annual International Tourist Arrivals}

The previous models were used to forecast international tourist arrivals for Amazonas, Pará, and the aggregate of the two states at both the monthly and annual frequencies for the years 2006 and 2007. The results along with observed data for 2006 are presented in Table 4. Five observations are pertinent. First, the annual aggregates of the monthly forecasts are less than the annual forecasts from the corresponding annual models, especially for Pará (specifically, 13,522 < 14,115; 13,123 < 17,881; and 29,280< 29,907). Second, the total annual forecast from the monthly models is greater than the aggregate of the annual forecasts for the monthly models for Amazonas and Pará (namely, 29,280 > 13,522 + 13,123). Third, the total annual forecast from the annual model is less than the sum of the annual forecasts for the annual models for Amazonas and Pará (namely, 29,907 < 14,115 + 17,881). Fourth, the annual forecasts for the total of Amazonas and Pará are very similar for the aggregate of the monthly model and the 
annual model (namely, 29,280 and 29,907). Finally, the forecast errors both for monthly and for annual models were much smaller for Pará than for Amazon and Total.

The forecasts along with observed data for 2007 are shown in Table 5. As in the case of the forecasts for 2006, five observations are useful. First, unlike the case for 2006, the annual aggregates of the monthly forecasts are greater than the annual forecasts from the corresponding annual models, for Amazonas and the total for the two states (specifically, 14,061 > 13,852; 12,362 < 17,425; and 29,808 28,804). Second, as for 2006, the total annual forecast from the monthly models is greater than the aggregate of the annual forecasts for the monthly models for Amazonas and Pará (namely, 29,808 $>14,061+12,362)$. Third, as in the case of 2006, the total annual forecast from the annual model is less than the sum of the annual forecasts for the annual models for Amazonas and Pará (namely, 28,804 < 13,852 + 17,425). Fourth, as for 2006, the annual forecasts for the total of Amazonas and Pará are very similar for the aggregate of the monthly model and the annual model (namely, 29,808 and 28,804). Finally, as in the case of 2006, the forecast errors for both monthly and annual models were much smaller for Pará than for Amazon and Total. In 2007, however, the annual model forecast error was much smaller than the annual forecast from the monthly models for Pará, while the opposite was observed in 2006.

Overall, the annual forecasts for the total of Amazonas and Pará are very similar for the aggregate of the monthly models and the annual models for 2006 and 2007. Thus, the forecasts suggest that there is not likely to be an marked increase in the number of international tourist arrivals to the Amazon rainforest between 2006 and 2007. This assertion is confirmed by the observed data also reported in Tables 4 and 5 , according to which there was only a $10.4 \%$ increase in the total number of international tourists arriving to those two Brazilian states between 2006 and 2007. 
As in the case of the observed international tourism arrivals data for the sample period, the monthly and annual forecasts of international tourism arrivals for 2006 and 2007 to Amazonas, Pará and the total for the two largest states in Brazil, suggest that international tourism arrivals to the Brazilian Amazon are very small. This fact would seem to point to the need for a much greater development of the sustainable tourist industry in the region.

\section{Concluding Remarks}

The paper modelled and forecasted sustainable international tourism demand for the Brazilian Amazon rainforest, which is one of the world's greatest natural wonders and holds great importance and significance for the world's environmental balance. In terms of fresh water volume, the Amazon River is by far the world's biggest, and the biodiversity in the Amazon region is one of the world's richest. The total extension of the Amazon rainforest is about 7 million square kilometers, and is distributed across nine South American countries. Around $60 \%$ of the Amazon rainforest located in the Brazilian territory, which corresponds to virtually the entire North region of the country, is called the Brazilian Amazon. Economic progress has been achieved at a cost of destroying large areas of the Amazon rainforest. In this scenario, the tourism industry would seem to have the potential to contribute to sustainable economic development in the Brazilian Amazon.

The two biggest states of the Amazon region are Amazonas (the upper Amazon) and Pará (the lower Amazon), which together account for around 73\% of the Brazilian Amazon. International tourist arrivals data were analysed for Amazonas and Pará, which are also the only two states in the Brazilian Amazon for which monthly time 
series data over an extended period are available. The paper discussed the monthly and annual international tourist arrivals to Amazonas, Pará and the total of the two states, presented unit root tests for the monthly and annual data, estimated alternative time series models and conditional volatility models of the shocks to international tourist arrivals, and provided forecasts of monthly and annual international tourist arrivals to Amazonas, Pará and the total of the two states for 2006 and 2007. The estimated models indicated that the persistence of shocks to international tourist arrivals was present in both the short and long run. As the second and fourth moment restrictions are satisfied for Amazonas and the total of Amazonas and Pará, the quasi maximum likelihood estimates were shown to be consistent and asymptotically normal, so that standard statistical tests were valid.

As in the case of the relatively low international tourism arrivals to the Brazilian Amazon for the 1971-2005 sample period for Amazonas and Pará, the forecasts of international tourism arrivals for 2006 and 2007 also suggested that the forecasted international tourism arrivals to the Brazilian Amazon were likely to be very small. These observations point to the need for a much wider development of the sustainable tourist industry in the Amazon rainforest region. Given the geographical size of the region and its natural beauty, appropriate marketing strategies should be directed at attracting a greater number of international tourists to the Brazilian Amazon. The development of a sustainable tourism industry is essential to the process of exploring the region rationally. Sustainable tourism would help to bring economic progress to the region without having negative impacts on the natural environment and the lives of the local communities.

In terms of the existent literature, this paper may be seen as a precursor for future analyses of sustainable tourism in the wider Amazon rainforest region as there 
would seem to be no previous research that has modelled and forecasted international tourist arrivals to the Amazon rainforest using reliable monthly time series data. Future research will investigate international tourism demand to the non-Brazilian Amazon, including the Peruvian Amazon and the Pantanal in Brazil.

\section{Acknowledgements}

The authors wish to thank the Editor and three referees for helpful comments and suggestions. The second author wishes to acknowledge the financial support of the Australian Research Council. 


\section{References}

Anwar, S. M., Jeanneret, C. A., Parrott, L., Marceau, D. J., 2007. Conceptualization and implementation of a multi-agent model to simulate whale-watching tours in the St. Lawrence Estuary in Quebec, Canada. Environmental Modelling \& Software 22, 1775-1787.

Athanasopoulos, G., Ahmed, R. A., Hyndman, R. J., 2009. Hierarchical forecasts for Australian domestic tourism. International Journal of Forecasting 25, 146-166.

Bollerslev, T., 1986. Generalised autoregressive conditional heteroscedasticity. Journal of Econometrics 31, 307-327.

Bonhama, C., Gangnesa, B., Zhoub, T., 2009. Modeling tourism: A fully identified VECM approach. International Journal of Forecasting (Forthcoming). Dickey, D.A., Fuller, W.A., 1979. Distribution of the estimators for autoregressive time series with a unit root. Journal of the American Statistical Association 74, 427431.

Dickey, D.A., Fuller, W.A., 1981. Likelihood ratio statistics for autoregressive time series with a unit root. Econometrica 49, 1057-1072.

Divino, J. A., Farias, A., Takasago, M., Teles, V.K., 2007. Tourism and economic development in Brazil. Unpublished paper. Centro de Excelencia em Turismo. University of Brasilia.

Elliott, G., Rothenberg, T. J., Stock, J. H., 1996. Efficient tests for an autoregressive unit root. Econometrica 64, 813-836.

Engle, R. F., 1982. Autoregressive cnditional hteroscedasticity with etimates of the variance of United Kingdom iflation. Econometrica 50, 987-1007. 
Gil-Alana, L. A. , Cunado, J., Gracia, F. P., 2008. Tourism in the Canary Islands: forecasting using several seasonal time series models. Journal of Forecasting 27, $621-636$.

Li, W. K., Ling, S., McAleer, M., 2002. Recent theoretical results for time series models with GARCH errors. Journal of Economic Surveys 16, 245-269. Reprinted in M. McAleer and L. Oxley (eds.), Contributions to Financial Econometrics: Theoretical and Practical Issues. Blackwell. Oxford, 2002, pp. 9-33.

Ling, S., Li, W. K., 1997. On fractionally integrated autoregressive moving-average models with conditional heteroskedasticity. Journal of the American Statistical Association 92, 1184-1194.

Ling, S., McAleer, M., 2002a. Stationarity and the existence of moments of a family of GARCH processes. Journal of Econometrics 106, 109-117.

Ling, S., McAleer, M., 2002b. Necessary and sufficient moment conditions for the GARCH(r,s) and asymmetric power GARCH(r,s) models. Econometric Theory 18, 722-729.

Ling, S., McAleer, M., 2003a. Asymptotic theory for a vector ARMA-GARCH model. Econometric Theory 19, 278-308.

Ling, S., McAleer, M., 2003b. On adaptive estimation in nonstationary ARMA models with GARCH errors. Annals of Statistics 31, 642-674.

McAleer, M., 2005. Automated inference and learning in modeling financial volatility. Econometric Theory 21, 232-261.

McAleer, M., Chan, F., Marinova, D., 2007. An econometric analysis of asymmetric volatility: theory and application to patents. Journal of Econometrics 139, 259284. 
McKenzie, C. R., McAleer, M., 1997. On efficient estimation and correct inference in models with generated regressors: A general approach. Japanese Economic Review 48, 368-389.

Ng, S., Perron, P., 2001. Lag length selection and the construction of unit root tests with good size and power. Econometrica 69, 1519-1554.

Oxley, L., McAleer, M., 1993. Econometric issues in macroeconomic models with generated regressors. Journal of Economic Surveys 7, 1-40.

Oxley, L., McAleer, M., 1994. Testing the rational expectations hypothesis in macroeconometric models with unobserved variables. In Oxley, L. et al. (eds.). Surveys in Econometrics. Blackwell, Oxford, pp. 299-349.

Pagan, A. R., 1984. Econometric issues in the analysis of regressions with generated regressors. International Economic Review 25, 221-247.

Pagan, A. R., 1986. Two stage and related estimators and their applications. Review of Economic Studies 53, 517-538.

Perron, P., Ng, S., 1996. Useful modifications to some unit root tests with dependent errors and their local asymptotic properties. Review of Economic Studies 63, 435463.

Phillips, P. C. B., Perron, P., 1988. Testing for a unit root in time series regression. Biometrika 75, 335-346.

Ribbe, J., Wolff, J.-O., Staneva, J., Grawe, U., 2008, Assessing water renewal time scales for marine environments from three-dimensional modelling: A case study for Hervey Bay, Australia. Environmental Modelling \& Software 23, 1217-1228.

Ticehurst, J. L., Newham, L. T. H., Rissik, D., Letcher, R. A., Jakeman, A. J., 2007. A Bayesian network approach for assessing the sustainability of coastal lakes in New South Wales, Australia. Environmental Modelling \& Software 22, 1129-1139. 
Figure 1 - Brazilian Amazon Map

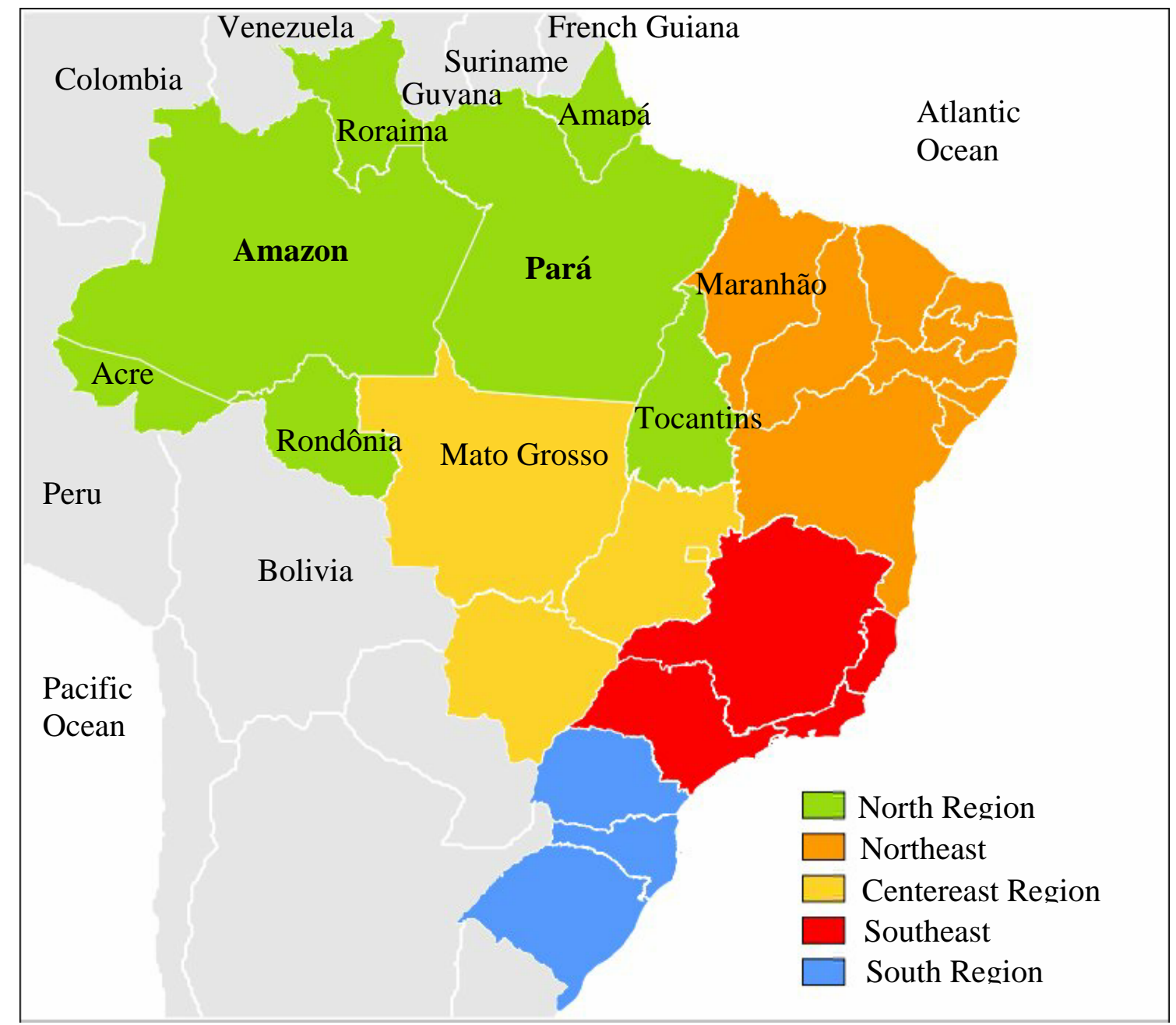

Source: Wikipedia. 
Figure 2 - Geographic Distribution of Tourism GDP by Municipal District

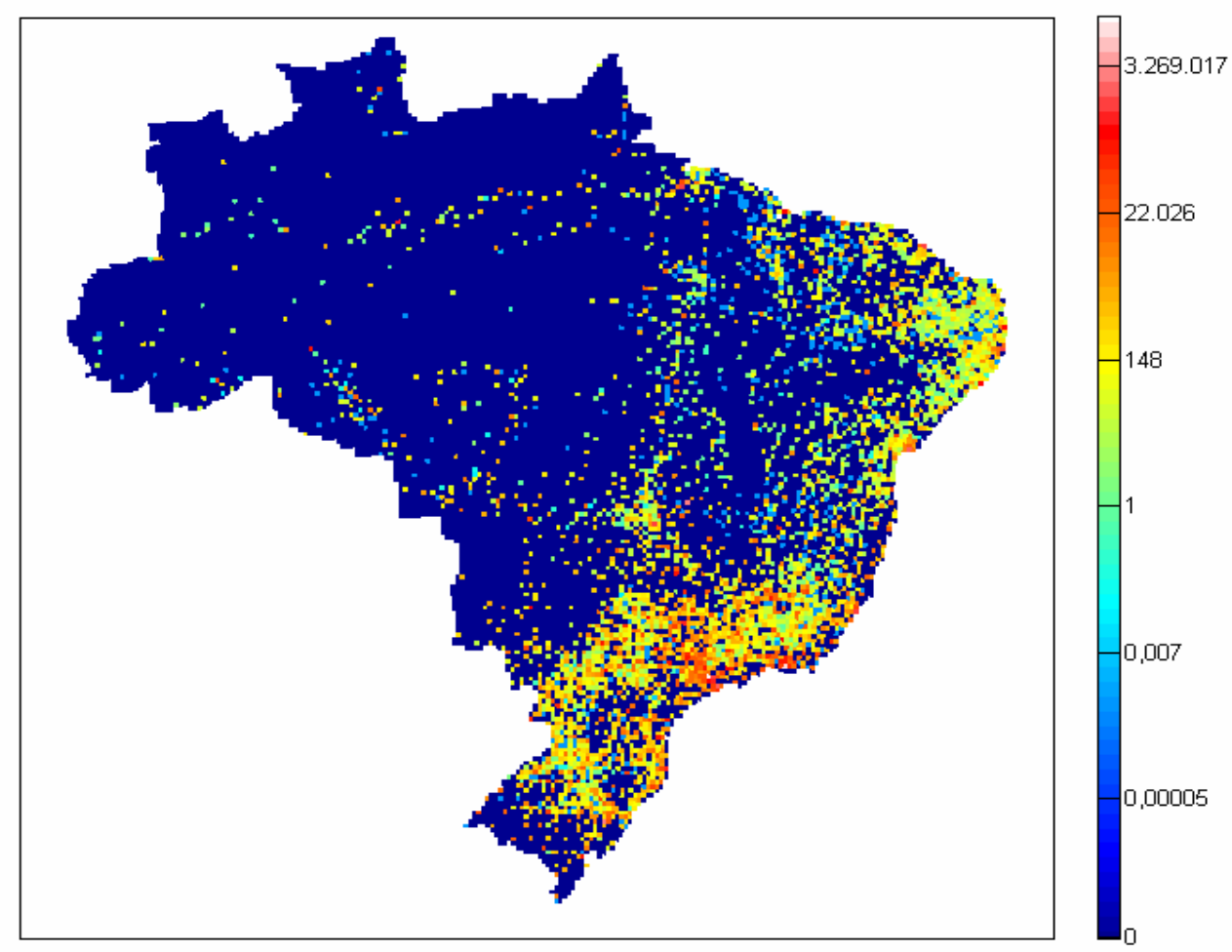

Note: The scale in the right-hand side is in $\mathrm{R} \$ 1,000$.

Source: Divino et al. (2007) 
Figure 3 - International Tourist Arrivals (monthly, Jan. 1971 to Dec. 2005)
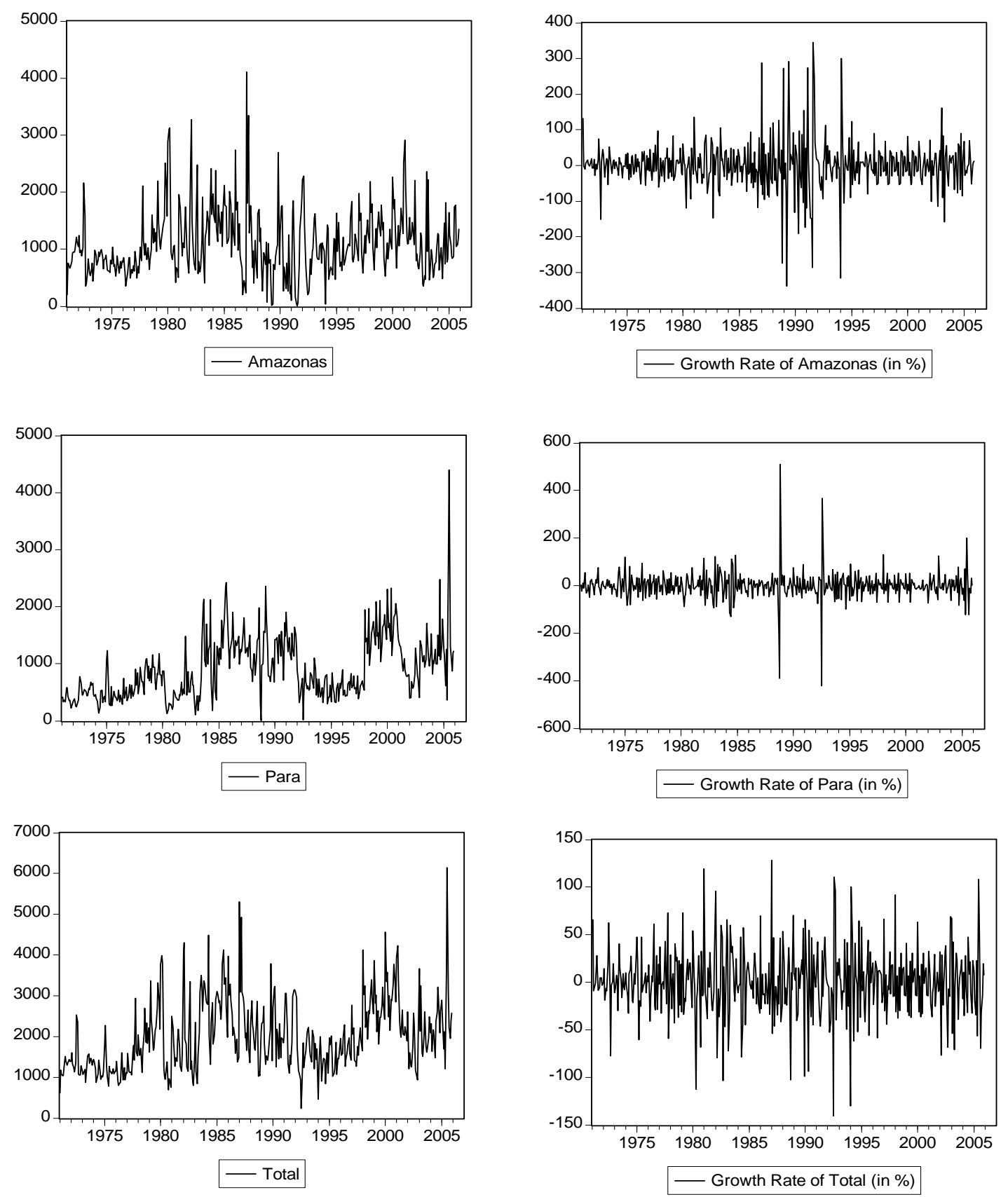
Figure 4 - International Tourist Arrivals (annual, 1971 to 2005)
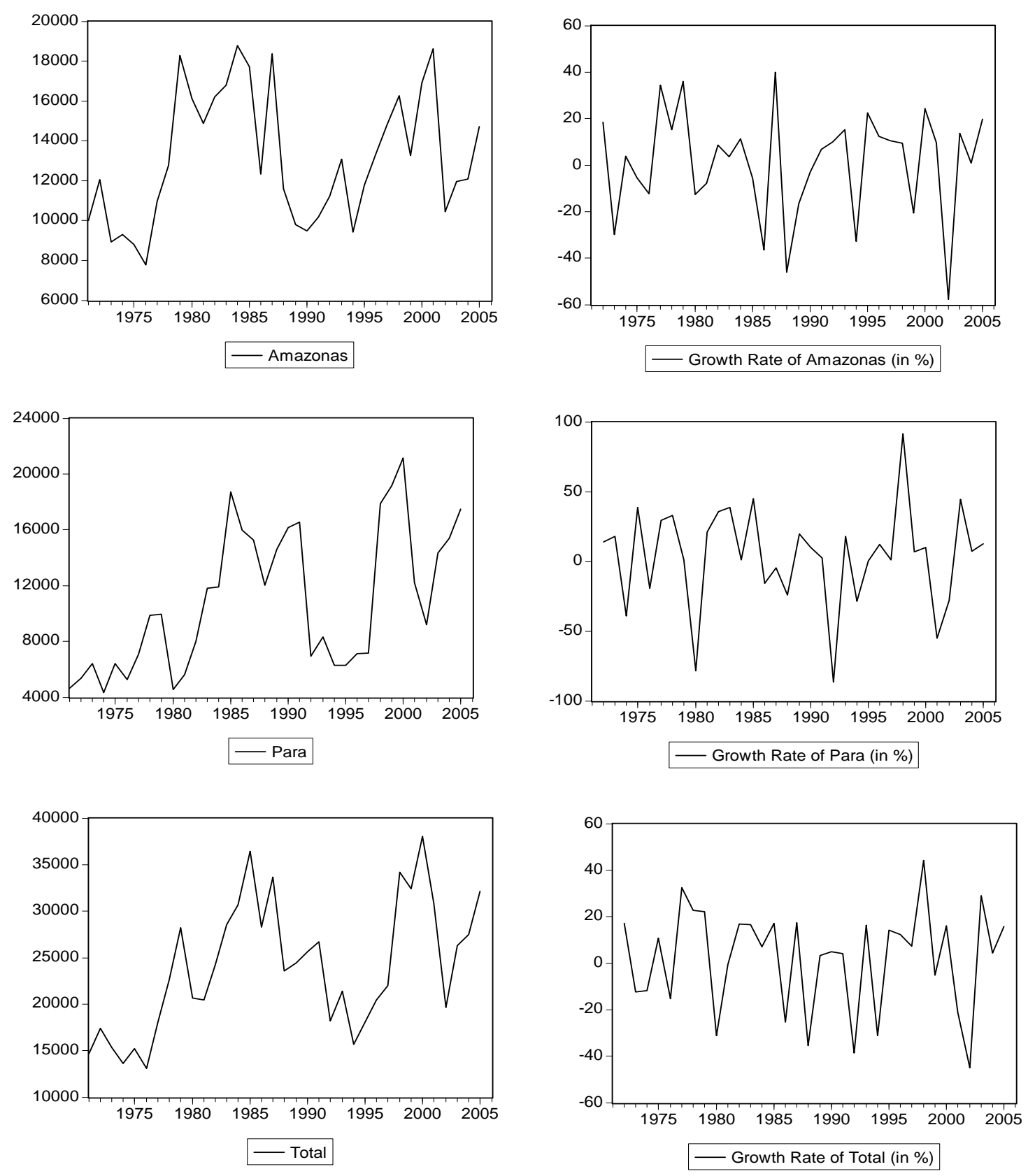
Table 1 - GDP of the Brazilian States

\begin{tabular}{lcc}
\hline \multicolumn{1}{c}{ State } & $\begin{array}{c}\text { GDP for } 2004 \\
\text { (US\$1,000) }\end{array}$ & $\begin{array}{c}\text { Per Capita GDP } \\
\text { for 2004(US\$) }\end{array}$ \\
\hline Distrito Federal & $10,105,241$ & 4,428 \\
Rio de Janeiro & $51,676,786$ & 3,399 \\
São Paulo & $126,916,064$ & 3,187 \\
Rio Grande do Sul & $33,173,817$ & 3,093 \\
Santa Catarina & $16,301,504$ & 2,823 \\
Amazonas & $\mathbf{8 , 3 3 2 , 9 3 2}$ & $\mathbf{2 , 6 5 5}$ \\
Paraná & $25,238,684$ & 2,490 \\
Espírito Santo & $8,007,710$ & 2,389 \\
Mato Grosso & $6,486,314$ & 2,359 \\
Mato Grosso do Sul & $4,632,989$ & 2,077 \\
Minas Gerais & $38,679,505$ & 2,036 \\
Goiás & $9,593,233$ & 1,742 \\
Amapá & $\mathbf{8 6 3 , 8 2 6}$ & $\mathbf{1 , 5 7 8}$ \\
Sergipe & $3,046,518$ & 1,575 \\
Bahia & $\mathbf{2 0 , 1 7 3 , 0 5 4}$ & 1,474 \\
Rondônia & $\mathbf{2 , 2 6 2 , 5 5 4}$ & $\mathbf{1 , 4 4 8}$ \\
Pernambuco & $11,074,819$ & 1,330 \\
Rio Grande do Norte & $3,693,226$ & 1,247 \\
Acre & $\mathbf{7 5 2 , 7 2 1}$ & $\mathbf{1 , 1 9 4}$ \\
Pará & $\mathbf{7 , 9 3 9 , 8 5 8}$ & $\mathbf{1 , 1 5 9}$ \\
Roraima & $\mathbf{4 3 2 , 8 3 5}$ & $\mathbf{1 , 1 3 3}$ \\
Ceará & $\mathbf{7 , 7 2 2 , 7 6 1}$ & 968 \\
Paraíba & $3,451,038$ & 967 \\
Alagoas & $2,683,229$ & 900 \\
Tocantins & $\mathbf{1 , 1 0 7 , 0 6 2}$ & $\mathbf{8 7 7}$ \\
Piauí & $1,999,475$ & 672 \\
Maranhão & $3,842,135$ & 638 \\
Southeast Region & $225,280,066$ & 2,912 \\
South Region & $\mathbf{7 4 , 7 1 4 , 0 0 5}$ & 2,805 \\
Middle-East Region & $30,817,777$ & 2,413 \\
North Region & $21,691,789$ & 1,509 \\
Northeast Region & $57,686,254$ & 1,144 \\
& & \\
Brasil & $410,189,891$ & \\
\hline
\end{tabular}

Note: The states of the North region are in bold. Values in descending order by per capita GDP. Source: Brazilian Institute for Geography and Statistics (IBGE), www.ibge.gov.br. 
Table 2 - Unit Root Tests

\begin{tabular}{lllllllll}
\hline \multirow{2}{*}{ Variable } & \multicolumn{5}{c}{ Monthly data } & \multicolumn{5}{c}{ Annual data } \\
\cline { 2 - 8 } & MADF & MPP & Lags & $\mathrm{Z}$ & MADF $^{\mathrm{GLS}}$ & MPP $^{\mathrm{GLS}}$ & Lags & $\mathrm{Z}$ \\
\hline LAM & -2.13 & -4.16 & 11 & $\{1, \mathrm{t}\}$ & -2.33 & -11.15 & 2 & $\{1, \mathrm{t}\}$ \\
LAM & -0.79 & -0.84 & 11 & $\{1\}$ & $2.11^{* *}$ & $-8.60^{* *}$ & 2 & $\{1\}$ \\
LPA & $-3.39 * *$ & $-20.11^{* *}$ & 13 & $\{1, \mathrm{t}\}$ & $-2.93^{* *}$ & -10.81 & 0 & $\{1, \mathrm{t}\}$ \\
LPA & $-4.73^{* *}$ & -1.53 & 13 & $\{1\}$ & $-1.94^{*}$ & $-6.06^{*}$ & 0 & $\{1\}$ \\
LTO & -1.85 & -4.08 & 16 & $\{1, \mathrm{t}\}$ & -2.35 & -9.49 & 1 & $\{1, \mathrm{t}\}$ \\
LTO & -0.25 & -0.16 & 16 & $\{1\}$ & -1.50 & -4.78 & 1 & $\{1\}$ \\
\hline
\end{tabular}

Notes:

LAM, LPA, and LTO denote the logarithm of international tourist arrivals to Amazonas, Pará and Total, respectively.

The critical values for MADF ${ }^{\mathrm{GLS}}$ and $\mathrm{MPP}^{\mathrm{GLS}}$ at the $5 \%$ significance level are -2.93 and -17.3 , respectively, when $\mathrm{Z}=\{1, \mathrm{t}\}$ and -1.94 and -8.1 when $\mathrm{Z}=\{1\}$. At the $10 \%$ significance level, the critical values are -2.57 and -14.2 , respectively, when $Z=\{1, t\}$ and -1.62 and -5.7 when $Z=\{1\}$.

$* *$ denotes the null hypothesis of a unit root is rejected at the $5 \%$ significance level.

* denotes the null hypothesis of a unit root is rejected at the $10 \%$ significance level. 
Table 3 - Estimated Conditional Mean and Conditional Volatility Models

\begin{tabular}{|c|c|c|c|c|c|c|}
\hline \multirow{2}{*}{ Variable } & \multicolumn{3}{|c|}{ Monthly } & \multicolumn{3}{|c|}{ Annual } \\
\hline & DLAM & DLPA & DLTO & DLAM & DLPA & DLTO \\
\hline Constant & $\begin{array}{l}0.003 \\
(0.001)\end{array}$ & $\begin{array}{c}-0.01 \\
(-0.01)\end{array}$ & $\begin{array}{c}0.002 \\
(0.003)\end{array}$ & $\underset{(0.01)}{0.01}$ & $\underset{(0.06)}{0.38}$ & $\begin{array}{l}0.38 \\
(0.06)\end{array}$ \\
\hline $\mathrm{AR}(1)$ & $\begin{array}{l}0.41 \\
(0.05)\end{array}$ & $\begin{array}{c}-0.16 \\
(0.07)\end{array}$ & $\underset{(0.06)}{0.44}$ & $\begin{array}{l}0.56 \\
(0.15)\end{array}$ & $\begin{array}{l}0.59 \\
(0.15)\end{array}$ & $\begin{array}{c}-0.70 \\
(0.13)\end{array}$ \\
\hline$A R(2)$ & --- & --- & --- & --- & --- & $\begin{array}{c}-0.61 \\
(0.15)\end{array}$ \\
\hline $\mathrm{AR}(12)$ & $\begin{array}{l}0.20 \\
(0.05)\end{array}$ & $\begin{array}{l}0.12 \\
(0.03)\end{array}$ & $\begin{array}{l}0.20 \\
(0.04)\end{array}$ & --- & --- & --- \\
\hline MA(1) & $\begin{array}{c}-0.98 \\
(0.02)\end{array}$ & $\begin{array}{c}-0.40 \\
(0.07)\end{array}$ & $\begin{array}{c}-0.92 \\
(0.02)\end{array}$ & $\begin{array}{c}-0.96 \\
(0.05)\end{array}$ & $\begin{array}{c}-0.98 \\
(0.04)\end{array}$ & $\begin{array}{l}0.71 \\
(0.06)\end{array}$ \\
\hline MA(2) & --- & --- & --- & --- & --- & $\begin{array}{l}0.96 \\
(0.05)\end{array}$ \\
\hline Constant & $\begin{array}{l}0.003 \\
(0.001)\end{array}$ & $\begin{array}{l}0.08 \\
(0.01)\end{array}$ & $\frac{0.002}{(0.001)}$ & --- & --- & --- \\
\hline $\operatorname{ARCH}(\alpha)$ & $\begin{array}{l}0.08 \\
(0.01)\end{array}$ & $\begin{array}{l}0.99 \\
(0.13)\end{array}$ & $\begin{array}{l}0.03 \\
(0.01)\end{array}$ & --- & --- & --- \\
\hline $\operatorname{GARCH}(\beta)$ & $\begin{array}{l}0.91 \\
(0.01)\end{array}$ & $\begin{array}{l}0.07 \\
(0.05)\end{array}$ & $\begin{array}{l}0.95 \\
(0.02)\end{array}$ & --- & --- & --- \\
\hline \multicolumn{7}{|l|}{ Diagnostics } \\
\hline LM(1) & $\begin{array}{l}0.20 \\
{[0.65]}\end{array}$ & $\begin{array}{l}0.03 \\
{[0.86]}\end{array}$ & $\begin{array}{l}0.00 \\
{[0.98]}\end{array}$ & $\begin{array}{l}0.05 \\
{[0.82]}\end{array}$ & $\begin{array}{l}2.41 \\
{[0.13]}\end{array}$ & $\begin{array}{l}0.00 \\
{[0.98]}\end{array}$ \\
\hline LM(2) & $\begin{array}{l}0.25 \\
{[0.78]}\end{array}$ & $\begin{array}{l}0.02 \\
{[0.98]}\end{array}$ & $\begin{array}{l}0.30 \\
{[0.74]}\end{array}$ & $\begin{array}{l}0.14 \\
{[0.87]}\end{array}$ & $\begin{array}{l}1.20 \\
{[0.32]}\end{array}$ & $\begin{array}{l}0.21 \\
{[0.81]}\end{array}$ \\
\hline
\end{tabular}

Notes:

DLAM, DLPA, and DLTO denote the log-differences, or growth rates, of international tourist arrivals to Amazonas, Pará and Total, respectively.

The numbers in parentheses are standard errors.

The numbers in brackets are p-values.

$\mathrm{LM}(1)$ and $\mathrm{LM}(2)$ are the Lagrange multiplier diagnostic tests for $\mathrm{ARCH}(1)$ and $\mathrm{ARCH}(2)$ residuals, respectively. 
Table 4 - Forecasts of International Tourist Arrivals for 2006

\begin{tabular}{lcccccc}
\hline & \multicolumn{7}{c}{ Monthly models } \\
\cline { 2 - 7 } & AM & AM-F & PA & PA-F & Total & Total-F \\
\hline January & 1,013 & 1,286 & 780 & 1,133 & 1,793 & 2,602 \\
February & 411 & 1,193 & 638 & 1,133 & 1,049 & 2,516 \\
March & 1,630 & 1,127 & 673 & 1,045 & 2,303 & 2,309 \\
April & 363 & 1,057 & 842 & 1,152 & 1,205 & 2,332 \\
May & 507 & 1,024 & 604 & 954 & 1,111 & 2,080 \\
June & 687 & 1,021 & 1,261 & 1,220 & 1,948 & 2,428 \\
July & 828 & 1,157 & 1,960 & 1,238 & 2,788 & 2,867 \\
August & 2,818 & 1,219 & 1,707 & 1,045 & 4,525 & 2,697 \\
September & 9,665 & 1,119 & 714 & 1,061 & 10,379 & 2,458 \\
October & 1,025 & 1,090 & 853 & 1,018 & 1,878 & 2,298 \\
November & 1,639 & 1,099 & 1,161 & 1,064 & 2,800 & 2,323 \\
December & 2,771 & 1,130 & 1,600 & 1,060 & 4,371 & 2,370 \\
Aggregate for 2006 & 23,357 & 13,522 & 12,793 & 13,123 & 36,150 & 29,280 \\
\cline { 2 - 7 } & \multicolumn{5}{c}{ Annual models } \\
\cline { 2 - 7 } & AM & AM-F & PA & PA-F & Total & Total-F \\
\cline { 2 - 7 } & 23,357 & 14,115 & 12,793 & 17,881 & 36,150 & 29,907 \\
\hline Annual Forecasts & \multicolumn{7}{c}{}
\end{tabular}

Notes: AM-F, PA-F, and Total-F denote the forecasts of international tourist arrivals to Amazonas, Pará, and Total, respectively. AM, PA, and Total denote actual international tourist arrivals to Amazonas, Pará, and Total, respectively. 
Table 5 - Forecasts of International Tourist Arrivals for 2007

\begin{tabular}{lcccccc}
\hline & \multicolumn{7}{c}{ Monthly models } \\
\cline { 2 - 7 } & AM & AM-F & PA & PA-F & Total & Total-F \\
\hline January & 2,809 & 1,176 & 2,369 & 1,045 & 5,178 & 2,444 \\
February & 1,964 & 1,179 & 1,339 & 1,044 & 3,303 & 2,461 \\
March & 1,454 & 1,170 & 1,525 & 1,030 & 2,979 & 2,432 \\
April & 2,312 & 1,154 & 1,143 & 1,043 & 3,455 & 2,430 \\
May & 1,717 & 1,142 & 1,091 & 1,014 & 2,808 & 2,383 \\
June & 1,331 & 1,139 & 821 & 1,052 & 2,152 & 2,447 \\
July & 2,223 & 1,169 & 2,477 & 1,044 & 4,700 & 2,561 \\
August & 1,161 & 1,194 & 1,390 & 1,021 & 2,551 & 2,579 \\
September & 1,813 & 1,187 & 1,285 & 1,023 & 3,098 & 2,547 \\
October & 1,700 & 1,180 & 1,328 & 1,014 & 3,028 & 2,507 \\
November & 2,283 & 1,181 & 1,092 & 1,018 & 3,375 & 2,502 \\
December & 1,416 & 1,190 & 1,883 & 1,014 & 3,299 & 2,515 \\
Aggregate for 2007 & 22,183 & 14,061 & 17,743 & 12,362 & 39,926 & 29,808 \\
\hline & AM & AM-F & PA & PA-F & Total & Total-F \\
\cline { 2 - 7 } & Annual models \\
Annual Forecasts & 22,183 & 13,852 & 17,743 & 17,425 & 39,926 & 28,804 \\
\hline
\end{tabular}

Notes: AM-F, PA-F, and Total-F denote the forecasts of international tourist arrivals to Amazonas, Pará, and Total, respectively. AM, PA, and Total denote actual international tourist arrivals to Amazonas, Pará, and Total, respectively. 